\title{
State Diagnosis of Macrozoobenthic Biodiversity in the Intertidal Zone of the Sandy Coast of Taghazout (Southwestern of Morocco)
}

\author{
Mohamed Ben Haddad', Imane Lamine', Abdellatif Moukrim², \\ Hafida Bergayou', Jaouad Abou Oualid', Aicha Ait Alla' \\ 1 Laboratory Aquatic Systems: Marine and Continental Ecosystems, Faculty of Sciences, Ibn Zohr University, \\ Agadir, Morocco \\ 2 Faculty of Sciences, Abdelamalek Essadi University, Tetouan, Morocco \\ * Corresponding authors email: m.benhaddad94@gmail.com
}

\begin{abstract}
The present work is a part of the impact study of the tourist resort "Taghazout Bay" installation on the coast of Taghazout (North of the Agadir bay). The purpose of this study was to assess the initial state of the macrozoobenthic structure present in the intertidal sands at the three study stations over the 2016 and 2017 seasons. The biological approach was accompanied by the study of some physico-chemical parameters of the seawater (temperature, $\mathrm{pH}$, salinity and dissolved oxygen) and the study of the sediment (grading structure, classification, and contents in organic matter). PCA analysis identified a perfect correlation between the physico-chemical parameters. The sediment contains three grading classes only (medium sand, fine sand, and very fine sand), very well classified with normal proportions of organic matter. The study of intertidal benthic macrofauna of the sandy substrate shows ten species and spatiotemporal variations with a clear dominance of the Donax trunculus bivalve species. The authors noticed - from the DIMO model - that the variation profile of the spring and summer (2016 and 2017) shows a community dynamics called "Diversity type". In winter and in autumn, they are known as the "Evenness type". The rank-frequency diagram explains that the benthic community of Taghazout sandy coast exists in the stage "Pioneer 1". The ascending hierarchical clustering gave three logical gatherings of seasons. The faunistic structure of this benthic community revealed the $\mathrm{M}>\mathrm{C}>\mathrm{P}$ shape. The authors also noticed that there is diversity in regimes in this ecosystem.
\end{abstract}

Keywords: Taghazout coasts, biodiversity, macro-zoobenthic structure, physico-chemical parameters, sediment.

\section{INTRODUCTION}

The region of Agadir has experience considerable development for a few years with numerous anchor projects for the various sectors (fishing, tourism, industry, agriculture etc.). Large parts of these development projects are located on the coast. As an example, a new large sea resort called Taghazout Bay (615 ha) is located on the shoreline of Taghazout, about fifteen kilometers from the Agadir city. This tourist project may provoke disturbances on the faunal and floral organizations, as well as on the physico-chemical quality of the seawater and the sediment. Besides the recent study on the microbiological quality of the Taghazout seawater (Lamine et al., 2019) and the study of Donax trunculus dynamics (Lamine et al., 2020), to our knowledge, no ecological study was realized at the coasts of Taghazout. In fact, the studies on the sandy beaches at the regional and national level are still rare. Otherwise, one can mention (Bayed, 2003; Bayed et al., 2008; Ana Maria et al., 2011; Lassalle et al., 2011; Gonzalez et al., 2014; Belal et al., 2019). In parallel, this kind of studies was often done in paralic environments (Bazairi et al., 2003; Gillet et al., 2003; Chaouti et al., 2005; Cherkaoui et al., 2005; Lefrere et al., 2015; Srinivas et al., 2017; Goransson et al., 2019; Bergayou et al., 2019). The authors intend to subsequently continue their studies on the ecosystem both before the construction of this tourist resort and after its implementation, in 
order to assess its environmental impact and to contribute to better management. The aim of this work was to assess the initial state of the macrozoobenthic biodiversity, which is one of the best biological tools that estimate the environmental change affecting ecosystems (Le Bris et al., 1996). The benthic macro-fauna plays a key role in the characterization and the functioning of the littoral ecosystems and constitutes a good indicator of their health (Chaouti et al., 2005; Gonzalez et al., 2014; Celentanoa et al., 2019). It is so closely correlated to the ecological conditions, which prevail in the interface water-sediment (Bayed, 2003; Lefrere et al., 2015). In this sense, undertook this work was undertaken, jointly, on the physico-chemical aspect (water and sediment) and on the biological communities of this sandy beach.

\section{MATERIALS AND METHODS}

\section{Study area}

The study site is located $15 \mathrm{~km}$ from the north of Agadir with a latitude and longitude of $30^{\circ}$ 30 '40" North and $9^{\circ} 40$ ' 33" West, respectively, hosting the touristic resort Taghazout Bay. The region is characterized by an arid to semi-arid climate influenced by relief, ocean, and Sahara, with a warm summer and concentrated rainfall during the winter, giving annual precipitation of about $300 \mathrm{~mm}$ (Mokhtari et al., 2013).

\section{Field sampling}

The benthic fauna was sampled at three stations (S1, S2 and S3) (Figure 1) with a seasonal periodicity during two years considering it as state zero "before the installation of a new large sea resort called Taghazout Bay" from spring 2016 to autumn 2017 (start of the sea resort installation). The samples were collected quantitatively and qualitatively at low tide by using a grab (surface: $1 \mathrm{~m}^{2}$ three times, depth: $50 \mathrm{~cm}$ ). For the purpose of identification, the samples were passed through a $1 \mathrm{~mm}$ mesh sieve and fixed in $8 \%$ formaldehyde. In the laboratory, the samples were rinsed in freshwater and preserved in $70 \%$ ethanol (Bachelet, 1993; Chaouti et al., 2005; Lefrere et al., 2015).

\section{Physico-chemical parameters of seawater and sediment}

Seawater temperature, salinity, $\mathrm{pH}$ and dissolved oxygen (DO) were recorded monthly in situ for two years (2016-2017) by the Thermo Scientific Orion StarTM A222. In order to measure particle grain size, the sediment samples $(100 \mathrm{~g})$ were taken from the zone where the specimens were collected at each station to a depth of 10 $\mathrm{cm}$. The collected samples were transported for 2 hours in a cooler at $4-6^{\circ} \mathrm{C}$. Once in the laboratory, they are stored at $-30^{\circ} \mathrm{C}$ until the time of analysis (4 to 6 days). The sediment samples were subsequently dried for 48 hours at $60^{\circ} \mathrm{C}$ (Bergayou,

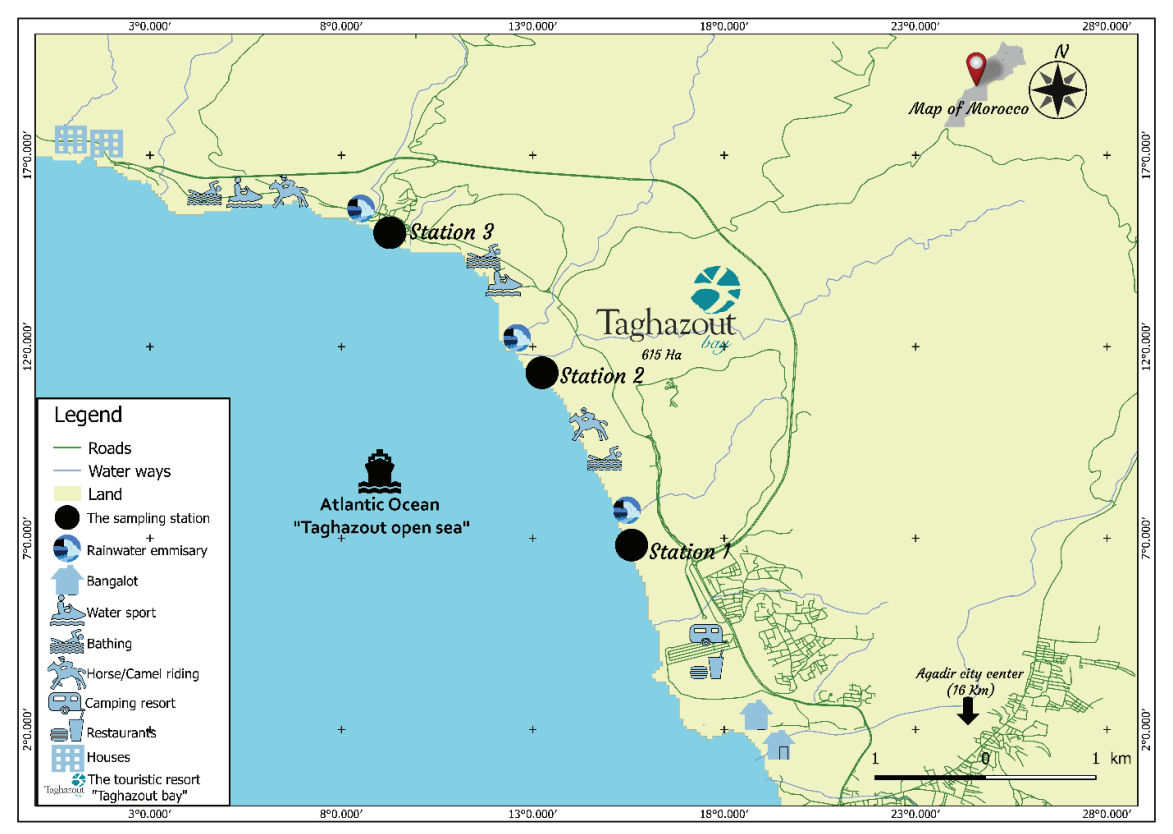

Fig. 1. Map of the study area (the studied stations are indicated) 
2006). The remaining sediment was dried again at a temperature of $60^{\circ} \mathrm{C}$, and all samples were then sieved through an AFNOR series of meshes (500, $315,250,200,160,125,100$, and $63 \mu \mathrm{m}$ ).

The classification of the sediment is estimated by the sorting index (Trask, 1932), S0 = [Q3/Q1] ${ }^{1 / 2}$ (1st Quartile Q1: abscissa which the ordinate corresponds to $25 \%$ of the weight and 3rd quartile Q3: abscissa which the ordinate corresponds to $75 \%$ ). The median particle size represents the diameter of the average grain of the sediment ( $50 \%$ of the weight).

For organic matter, the top $15 \mathrm{~cm}$ of sediment was sampled every month and the organic matter content of the sediment was determined by the loss of weight on ignition using the Muffle furnace Heraeus M110 $\left(4 \mathrm{~h}\right.$ at $\left.550^{\circ} \mathrm{C}\right)$ after drying to constant weight $\left(72 \mathrm{~h}\right.$ at $\left.65^{\circ} \mathrm{C}\right)$ a homogenized portion of about $100 \mathrm{~g}$ of sediment (CEAEQ, 2003).

\section{Biomass and density}

At each sampling station, the biomass of benthic fauna was considered by drying all the individuals at $80^{\circ} \mathrm{C}$ over $48 \mathrm{~h}$ (dry weight). Then, they were placed at $600^{\circ} \mathrm{C}$, for calcination for two hours (weight of ashes). Molluscs, in particular, underwent a preliminary decalcification in a bath of $\mathrm{HCl} 10 \%$. The difference between the decalcified dry weight and the weight of ashes supplies the organic weight free of ash (Gillet et al., 2003; Horn et al., 2016; Bergayou et al., 2019). Density was estimated in terms of the number of individuals of fauna harvested per square meter (ind. $\mathrm{m}^{-2}$ ) at a depth of $50 \mathrm{~cm}$.

A graphic presentation of the biomass (Ashes and dry weight "A.D.W." in g. $\mathrm{m}^{-2}$ ) with the density $\left(\mathrm{N} / \mathrm{m}^{2}\right)$ was made.

\section{Communities characterization of the macrozoobenthic biodiversity}

A characterization by the diversity indices of Shannon-Wiener H', equitability J' and specific richness S (Pielou, 1966) was carried out. The three indices H', J' and S were considered in the DIMO model (Qinghong, 1995) using a synthetic graphic representation which allows visualizing simultaneously the values of these indices. The characterization of the demographic structure of the benthic macrofauna was made by the rankfrequency diagram (Frontier, 1976) in order to classify every station in one of the three stages of
Frontier based on the shape of curves. The trophic structure of the populations was established based on the criteria proposed by several authors (Hily, 1978; Lassalle et al., 2011; Hossain, 2019) as well as according to its morphological and ethoecological characteristics (Cherkaoui et al., 2005; Chaouti et al., 2005).

\section{Statistical analysis}

In order to reveal the correlation between the physico-chemical parameters, we carried out the Principal Component Analysis (PCA) with XLSTAT for Microsoft Excel 2013. An ascending hierarchical clustering with the software Statistica v6.1 was realized to see if there is a gathering of similar seasons and to better detect the seasonal variation. The study of the significant difference in this work was made by XLSTAT and Statistica v6.1.

\section{RESULTS}

\section{Physico-chemical parameters of seawater}

Figure 2 shows the temporal variation of temperature, $\mathrm{pH}$, salinity and dissolved oxygen during the sampling period in the studied stations. Water temperature showed seasonal variations values with fluctuations from $14.9{ }^{\circ} \mathrm{C}$ in winter (February 2016) to $26.6{ }^{\circ} \mathrm{C}$ in summer (August 2017). These variations are related to atmospheric temperature fluctuations (Figure 2, T). Concerning salinity, fluctuations among years were observed with the lowest values of $26.9 \mathrm{~g} / 1$ and $31.26 \mathrm{~g} / 1$ recorded in winter (February 2016 and 2017, respectively), while the maximum value was observed in summer (August 2016 and 2017) with the values of $35.2 \mathrm{~g} / \mathrm{l}$ and $37.9 \mathrm{~g} / \mathrm{l}$ respectively (Figure 2, S). The seasonal evolution of dissolved oxygen shows the highest value in March 2017 with $8.5 \mathrm{mg} / \mathrm{l}$, while the lowest value was recorded in winter (November 2016 and October 2017) with $6.9 \mathrm{mg} / \mathrm{l}$ (figure 2, DO).The values of the $\mathrm{pH}$ recorded oscillate between 7.04 in winter (February 2016) and 8.17 in summer (August 2017) (Figure 2, pH).

The obtained results show that there are no significant differences in physico-chemical parameters between both stations and years $(p>0.05)$ except salinity that showed a significant difference $(p<0.05)$ between the values obtained in 2016 and 2017. The projection of the 

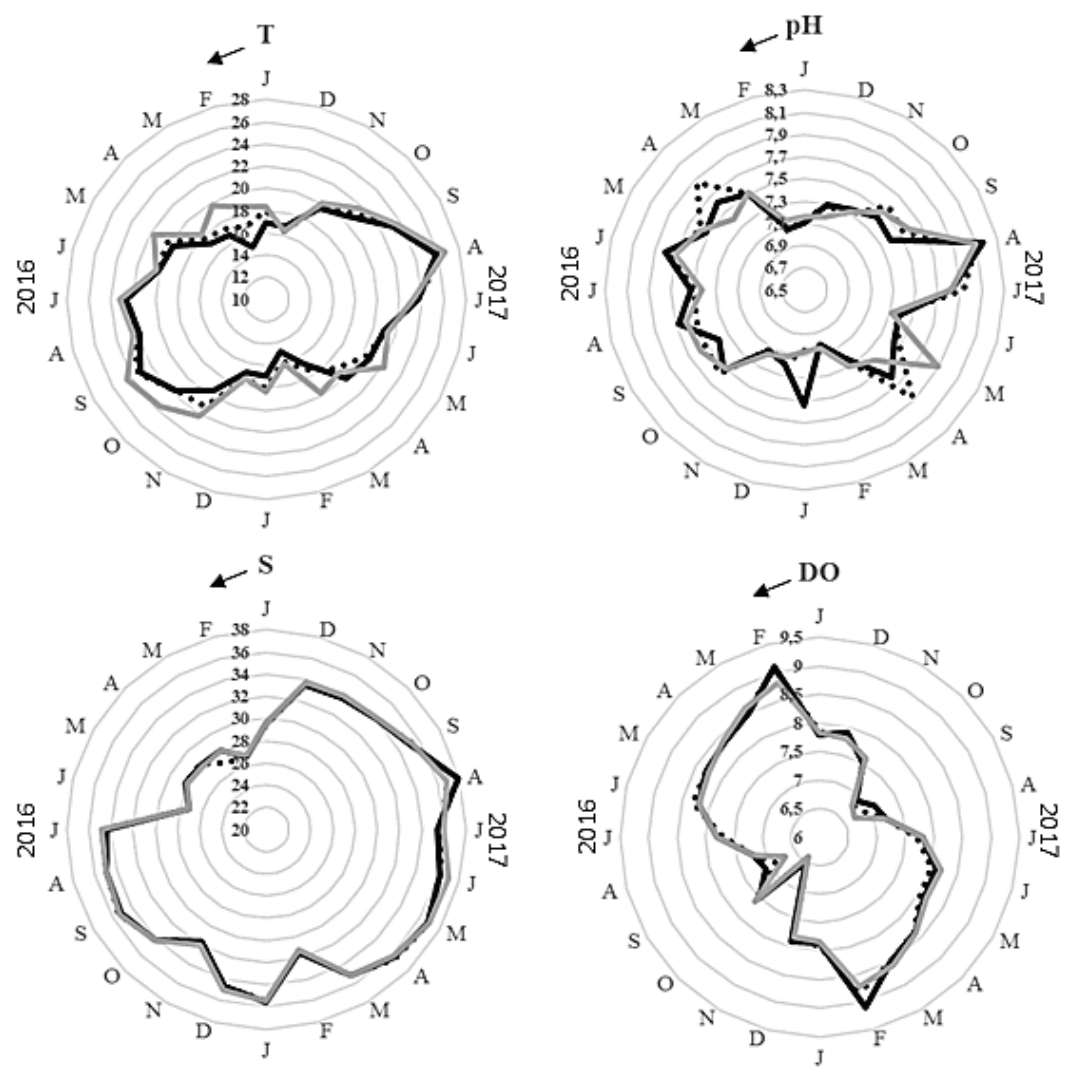

T: Temperature, S: Salinity, pH: Potiential of Hydrogen, DO: Dissolved Oxygen

Fig. 2. Radar presentations of temporal variations in water temperature, salinity, pH and dissolved oxygen during two years (2016-2017)

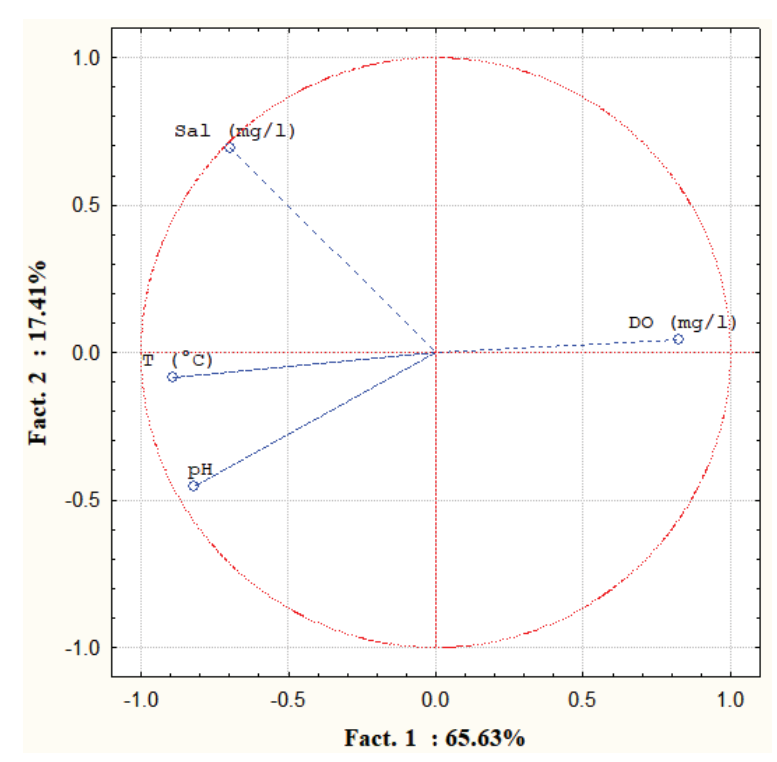

Fig. 3. Principal component analysis between temperature, $\mathrm{pH}$, dissolved oxygen and salinity

physico-chemical parameters (temperature, $\mathrm{pH}$, dissolved oxygen and salinity of 24 months 20162017) by considering the average of three stations on the factorial plans $(1 \times 2)$ reveals two factorial axes $\mathrm{F} 1$ and $\mathrm{F} 2$, which express $83.04 \%$ of the total variance (figure 3 ). The axis F1 adds up $65.63 \%$ of the total variance. It is defined in its negative part essentially by the $\mathrm{pH}(\mathrm{r}=-0.81)$ and the temperature $(r=-0.89)$. In its positive part, it is defined by the variation of dissolved oxygen in seawater $(\mathrm{r}=0.82)$. The axis F2 accumulates $17.41 \%$ of the total variance. It is essentially correlated to the variation of the salinity $(r=0.72)$.

\section{Granulometry and organic matter of the sediment}

In the spatiotemporal variation study of the median particle size of the sediment, it was noticed that there is a very highly significant difference between the seasons $(p<0.001)$ and no significant difference between stations. The minimal value was registered in spring 2017 (196.6 55.7$)$ and the maximal value was detected in autumn

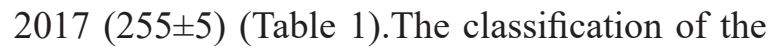
sediment (Trask index) reveals a significant difference $(p<0.05)$ between seasons. However, there is no significant difference between stations. The maximum value does not exceed 1.0, it was registered in spring $2016(0.8 \pm 0.13)$ and 
Table 1. Median particle size and trask index values in both seasons and stations

\begin{tabular}{|c|c|c|c|c|c|c|c|}
\hline \multirow{2}{*}{ Station } & \multicolumn{7}{|c|}{ Median particle size $(\mu \mathrm{m})$} \\
\hline & Spring16 & Summer16 & Autumn16 & Winter17 & Spring17 & Summer17 & Autumn17 \\
\hline S1 & $216.7 \pm 11.5$ & $246.6 \pm 2.8$ & $238.3 \pm 16.0$ & $208.3 \pm 12.5$ & $196.6 \pm 5.7$ & $233.3 \pm 20.8$ & $250 \pm 8.6$ \\
\hline S2 & $223.3 \pm 15.2$ & $245 \pm 5.0$ & $235 \pm 21.7$ & $210 \pm 10.0$ & $213.3 \pm 5.7$ & $235 \pm 22.9$ & $255 \pm 5.0$ \\
\hline S3 & $213.3 \pm 15.2$ & $241.6 \pm 7.6$ & $231.6 \pm 27.5$ & $210 \pm 10.0$ & $213.3 \pm 15.2$ & $240 \pm 26.4$ & $250 \pm 5.0$ \\
\hline \multicolumn{8}{|c|}{$p$ (saisons) $=5.06 .10^{-08}\left({ }^{\star * *}\right)$} \\
\hline \multicolumn{8}{|c|}{$p($ stations $)=0.84$} \\
\hline \multirow{2}{*}{ Station } & \multicolumn{7}{|c|}{ Trask index $\left(\mathrm{S}_{0}\right)$} \\
\hline & Spring16 & Summer16 & Autumn16 & Winter17 & Spring17 & Summer17 & Autumn17 \\
\hline S1 & $0.8 \pm 0.03$ & $0.76 \pm 0.07$ & $0.73 \pm 0.04$ & $0.72 \pm 0.04$ & $0.76 \pm 0.01$ & $0.72 \pm 0.04$ & $0.73 \pm 0.05$ \\
\hline S2 & $0.8 \pm 0.10$ & $0.74 \pm 0.05$ & $0.73 \pm 0.03$ & $0.75 \pm 0.03$ & $0.70 \pm 0.05$ & $0.68 \pm 0.10$ & $0.75 \pm 0.09$ \\
\hline S3 & $0.8 \pm 0.13$ & $0.75 \pm 0.05$ & $0.72 \pm 0.02$ & $0.76 \pm 0.02$ & $0.75 \pm 0.01$ & $0.74 \pm 0.03$ & $0.76 \pm 0.11$ \\
\hline \multicolumn{8}{|c|}{$p$ (saisons) $=0.028\left(^{*}\right)$} \\
\hline \multicolumn{8}{|c|}{$p($ stations $)=0.71$} \\
\hline
\end{tabular}

the minimum value is not lower than 0.5 , it was detected in summer $2017(0.68 \pm 0.10)$ (Table 1).

There was no significant difference $(p>0.05)$ between three stations. Therefore, the results of the classes were presented in Shepard's (1954) diagram for every season by considering the average of the stations. This diagram displays the state of the sediment in every season in its place according to its composition in grading classes. The sediment of Taghazout coast revealed three grading classes (medium sand, fine sand, and very fine sand). It was noticed that the medium sand occupies the majority of the grading composition, followed by the fine sand and then the very fine sand, which presents very small proportions.

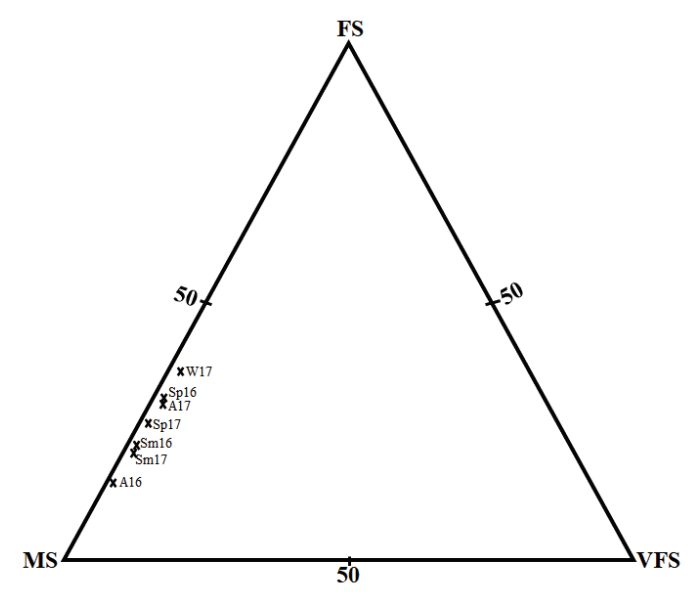

Fig. 4. Positioning of the seasons in the triangular diagram of Shepard (using average of stations:

FS - Fine Sand, MS - Medium Sand, VFS - Very

Fine Sand, W16 - Winter 2016, Sp16, Sp17 - Spring

2016 and 2017, Sm16, Sm17 - Summer 2016 and 2017, A16, A17 - Autumn 2016 and 2017
The variation of sediment state is mainly related to the variation of the rate of medium sand. Autumn 2016, summer 2016 and summer 2017 are the seasons, which present the highest percentage of the medium sand $(83.24 \pm 1.1 \%, 80 \pm 0.5 \%$, and $79.9 \pm 0.7 \%$, respectively). On the other hand, winter 2017 presents the lowest percentage (63.35 $\pm 0.51 \%)$ (Figure 4).

The sediment of the studied ecosystem revealed an organic matter variation between a minimum of $0.532 \pm 0.04 \%$ (in May 2016) and a maximum of $2.86 \pm 0.06 \%$ (in September 2017). It was noticed that there is no significant difference between the three stations ( $p>0.05)$, but between months, there is a very highly significant difference $(\mathrm{p}<0.001)$. Between 2016 and 2017, an increase in the organic matter rate can be noticed (2016: $0.95 \pm 0.16 \%$ and 2017: $1.65 \pm 0.45 \%)$, particularly after June 2017 $(1.93 \pm 0.38 \%)$ (Figure 5).

\section{Study of macrobenthic fauna}

\section{Density and biomass}

The density and the biomass present important seasonal fluctuations. The maximum peak of the density was recorded in spring 2016 at station $2\left(316 \pm 10\right.$ ind. $\left.\mathrm{m}^{-2}\right)$ and the minimum value was detected in winter $2017\left(56 \pm 5\right.$ ind. $\left.\mathrm{m}^{-2}\right)$ at all stations. The density decreases from spring 2016 to winter 2017, then it increases again from spring 2017. As for the biomass, it shows two extreme values, a maximum in summer $2017(95.21 \pm 6$ A.D.W in g. $\mathrm{m}^{-2}$ ) and a minimum in winter 2017 (3.8 \pm 0.2 A.D.W in g. $\mathrm{m}^{-2}$ ) (Figure 6). 


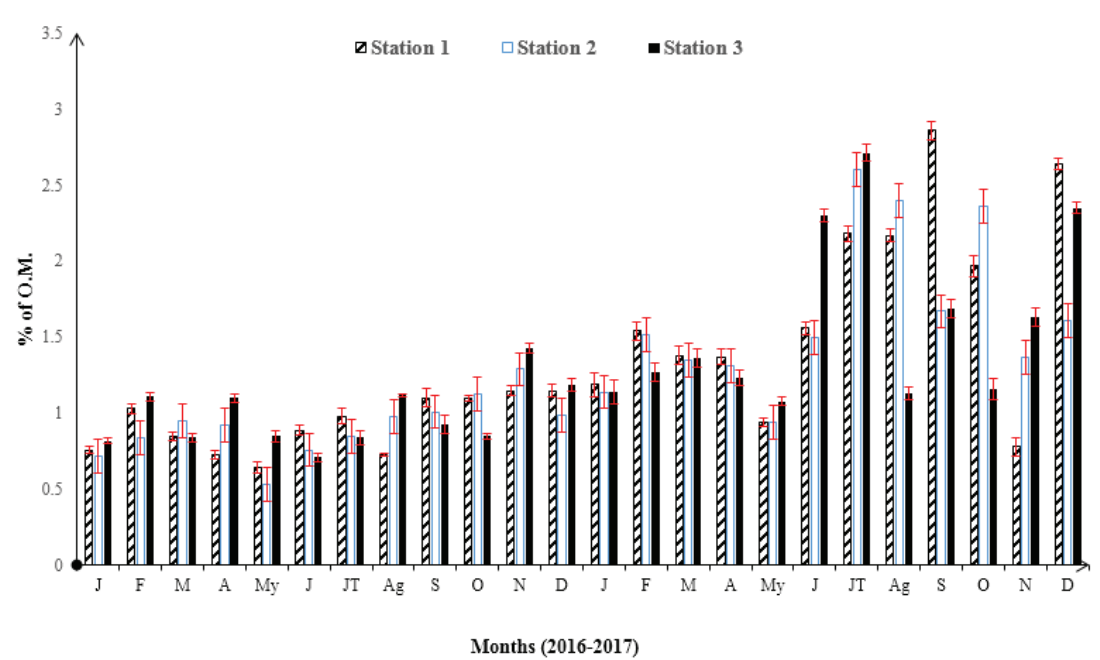

Fig. 5. Variations of organic matter from January 2016 to December 2017 at the three stations

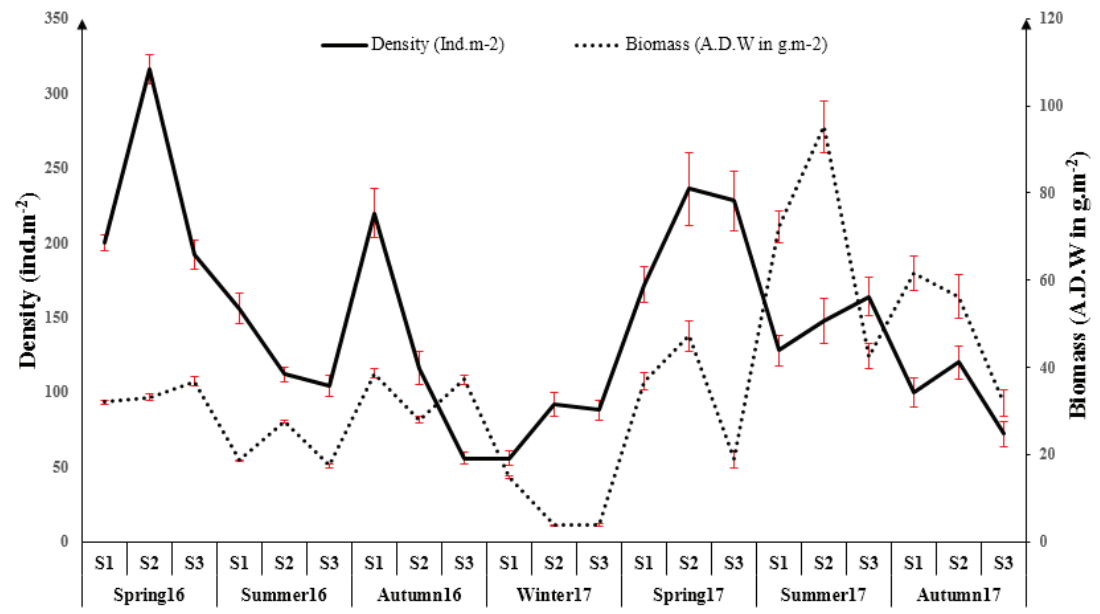

Fig. 6. Spatiotemporal variations of species density (ind. $\mathrm{m}^{-2}$ ) and biomass (A.D.W in g. $\mathrm{m}^{-2}$ )

\section{Spatio-temporal variation of macrozoobenthic fauna and hierarchical clustering (CHA) of seasons}

During the study period, ten species were counted and a remarkable spatiotemporal variation was obserced. The Donax trunculus mollusk was the dominant species in the Taghazout sandy ecosystem. It exists in all the stations during all the seasons. The Turritella communis species is the best accompanying of $D$. trunculus in the benthic community, it is absent only at station 3 in summer 2016 and the stations 1 and 2 in autumn 2016. The Macomangulus tenuis, Portumnus latipes, and Marphysa sanguina species are less frequent and they indicate important spatiotemporal variations. For Cymbium cucumis was noticed to occupy the beach at soft and hot periods. The Nemertea sp., Talitrus saltator, Natica royi, and Eurydice pulchra species were rare. They exist in Taghazout sandy ecosystem in spring and summer essentially. In turn, it was noticed that the winter period shows the lowest diversity compared to the other seasons (Table 2).

The ascending hierarchical clustering (AHC) presents a classification by dissimilarity (Chisquare distance) of the seasons basing on the variation of the species abundance. It showed a first gathering which contains summer 2016, autumn 2017 and summer 2017; the second gathering which moves closer winter 2017 with autumn 2017 and a third gathering which contains two springs (2016 and 2017) (Figure 7).

\section{Analytic characterization by DIMO (Species diversity monitoring) model and RF (Rank-Frequency) diagram}

The DIMO model (Figure 8) allowed us to reveal and to follow the change of three indices 
Table 2. Spatiotemporal variation (stations and seasons) of the collected macrozoobenthic species

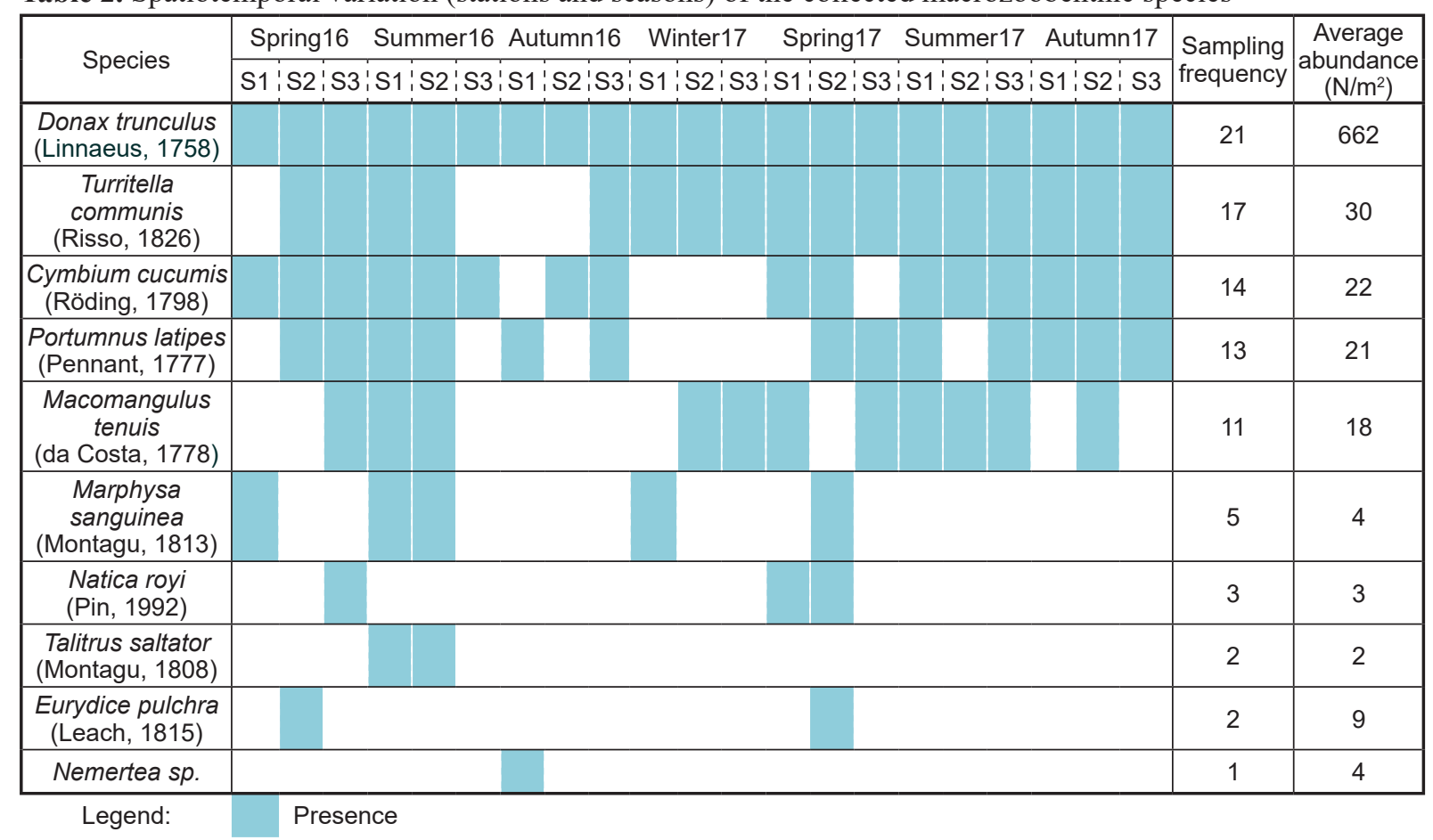

in a synthetic way (Specific richness S, Diversity H' and Equitability J') considering both stations and seasons. Spring 2016 (Station 3), spring 2017 (station 2) and summer 2016 (station 1) are the seasons which present the maximum values of species richness. On the contrary, the winter 2017 (all the stations) and autumn 2017 (station 3 ) show the minimum in species richness. The diversity H' presents a maximum in summer 2016 (station 1), spring 2017 (all the stations) and summer 2017 (all the stations). However, in autumn 2016 and winter 2017, H' was minimal at all the stations. Equitability J' is proportional to the degree of angle between the point and the axis of species richness. It was noticed that the winter and the autumn are the seasons with the lowest values of equitability J', while the summer and the spring show the highest values.

The rank-frequency diagram is realized for the three stations. The variation profile of diagrams is presented in figure 9. The stations show characteristic curves of a stage called "Pioneer 1" because the macrobenthic community shows a weak diversity. These curves indicate the presence of

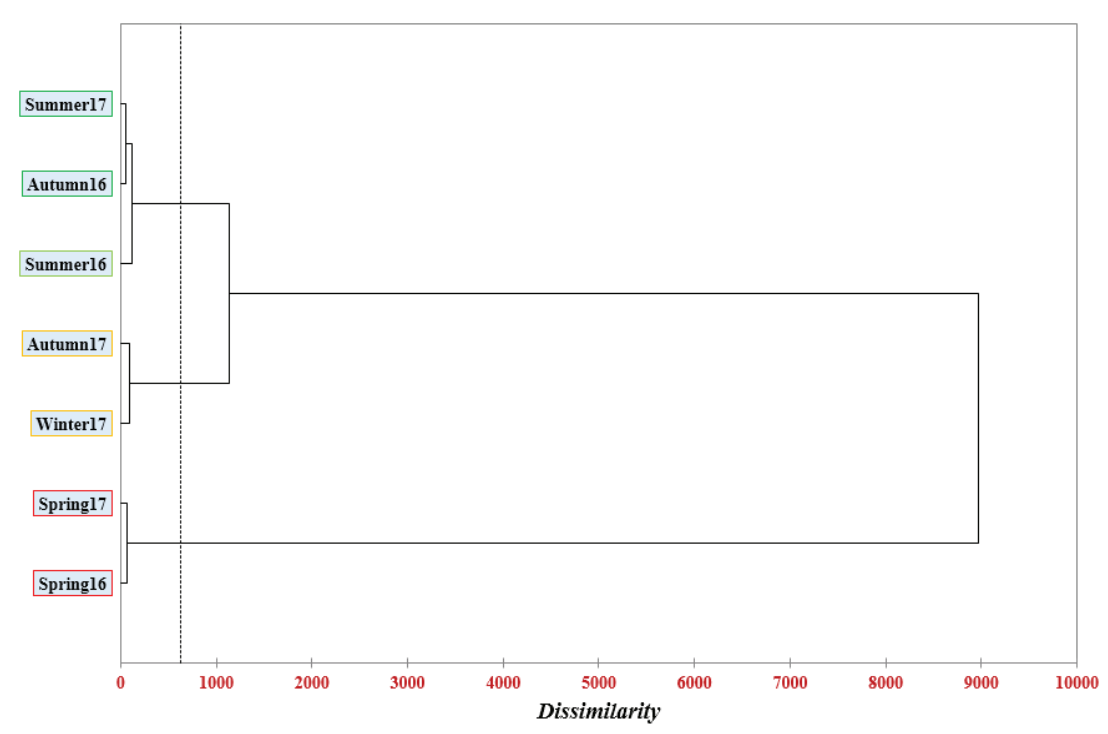

Fig. 7. Ascending hierarchical clustering of the seasons using chi-square distance 


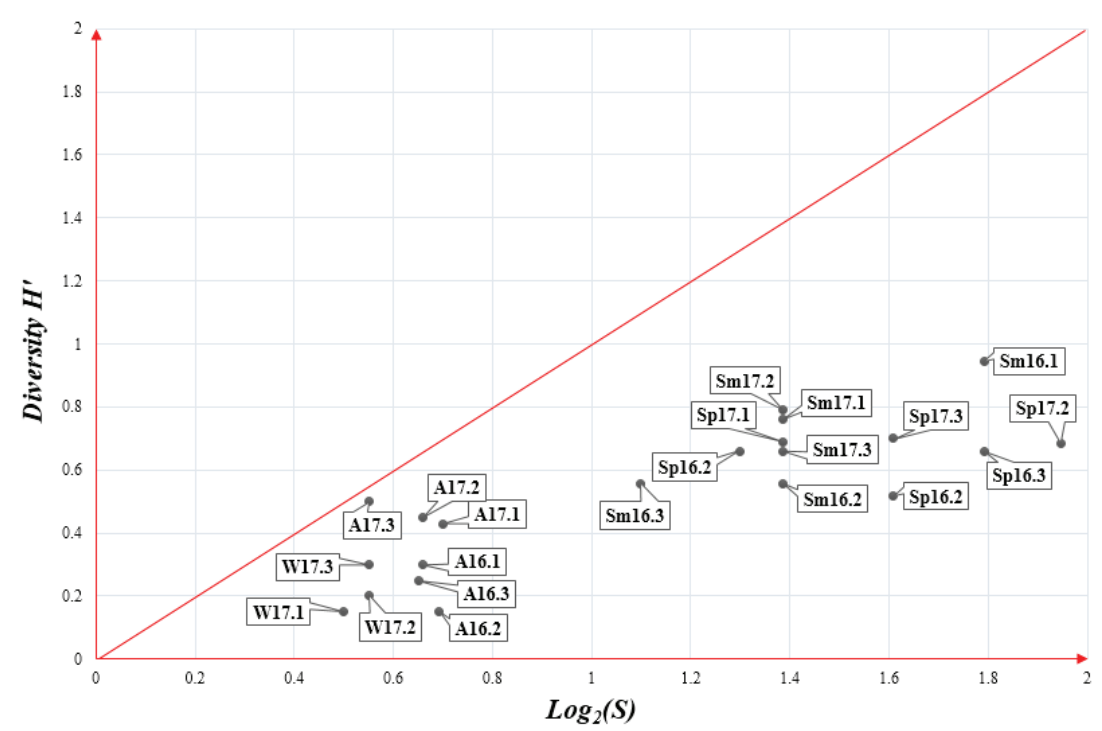

Fig. 8. Graphic presents DIMO model. (Sm/Sp/A/W: Summer, Spring, Autumn and Winter. 16/17: 2016 and 2017. 1/2/3: station 1, station 2 and station 3)

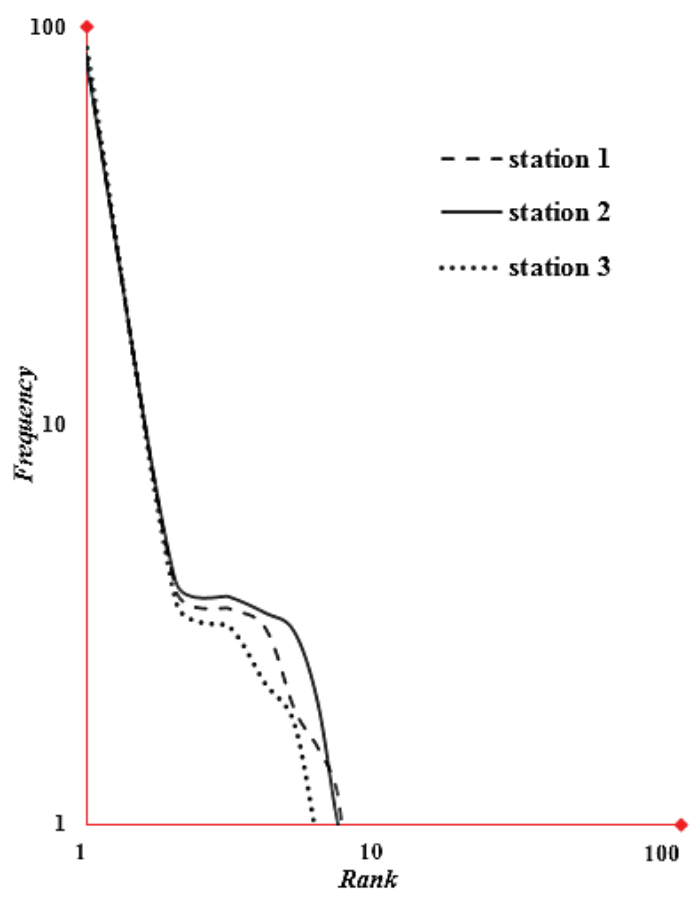

Fig. 9. Rank-frequency diagram of station 1,2 and 3

a weak number of plentiful species, followed by averagely plentiful species. Comparing between stations, it can be noticed that the curve of the station 2 shows a higher regularity.

\section{Faunistic and trophic composition}

The faunistic structure of the benthic community of Taghazout sandy coast presents four taxonomic groups. Molluscs, with $50 \%$ of the composition, Crustaceans with $30 \%$ as well as Worms

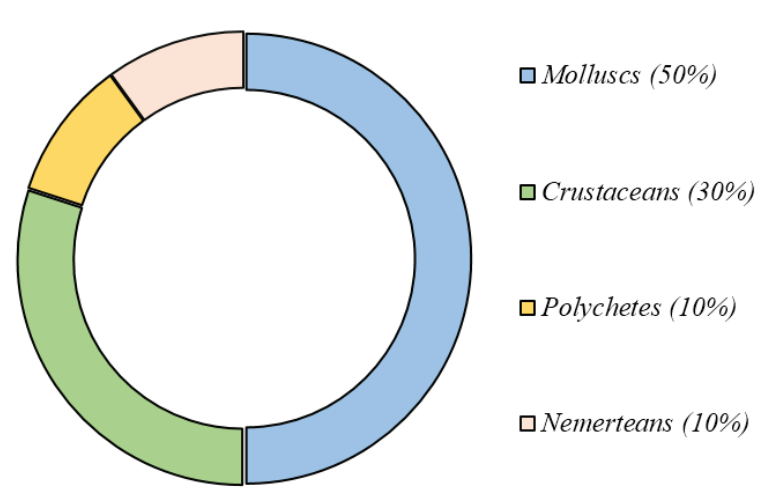

Fig. 10. Pie chart presents the faunistic composition of the benthic community

polychetes and Nemerteans which present $10 \%$ each (Figure 10). As for the trophic composition, the suspension feeders and omnivorous species are present in this ecosystem in all the seasons. In winter 2017, the absence of the carnivorous predator species can be noticed. The surface deposit feeders are present in all the seasons with the exception of autumn 2016. The scavenger species are present only in spring 2016 and 2017, summer 2016 and autumn 2016 (Fig.11).

\section{DISCUSSION}

\section{Physico-chemical parameters of seawater and sediment characteristics}

The study of physico-chemical parameters of seawater shows that there is a strong correlation between temperature, $\mathrm{pH}$ and dissolved oxygen. 


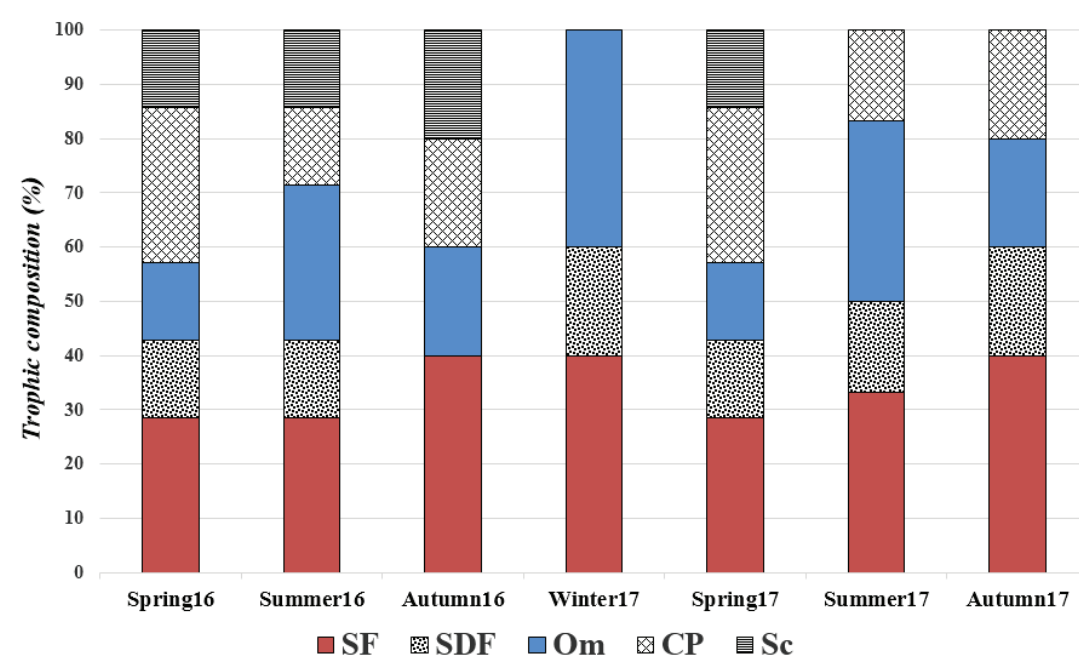

Fig. 11. Graphic presents the trophic composition of the benthic community: SF - Suspension feeder, $\mathrm{SDF}$ - Surface deposit feeder, Om - Omnivorous, $\mathrm{CP}$ - Carnivorous predator and $\mathrm{Sc}-\mathrm{Scavenger}$

In other words, the more the temperature and the $\mathrm{pH}$ increase, the greater the dissolved oxygen decrease. On the other hand, it was noticed that during the studied period, there are simultaneous seasonal variations of three elements in connection with the archetypal climatic variations (correlation with the moderate air temperature is $98 \%$ ), the same thing is noticed by Bayed (2003). The salinity straddles the axis $\mathrm{F} 1(\mathrm{r}=0.70)$ and the axis $\mathrm{F} 2(\mathrm{r}=0.70)$ because it is strongly correlated with the temperature $(r=88 \%)$, but it defines mainly the axis F2. This parameter was well-studied in a sandy beach along an estuarine gradient by (Orlando et al., 2020) revealing that specific richness is very important when it exceeds $27.2 \mathrm{mg} / 1$.

The sediment contains three grading classes only (medium sand, fine sand, and very fine sand). In the sandy beaches of Morocco, several studies have found these three classes with different proportions (Bayed, 2003; Bayed et al., 2008). The proportion of fine sand in the beach considered in this study is low comparing to other sandy beaches (Rodil et al., 2014 ; Sibaja-Cordero et al., 2019). Furthermore, the studies on more complex sediments in lagoons and estuaries revealed other classes (Bazairi et al., 2003; Gillet et al., 2003; Chaouti et al., 2005; Cherkaoui et al., 2005; Bergayou et al., 2019). By studying the classification of sediments, it can be seen that all the values are between 0.5 and 1 , so it may be considered that the sediments during the whole study period are very well classified (Trask, 1932), which indicates a stable state of the sediments. A similar study in Costa Rica revealed the values between 1 and 2.5 (Sibaja-Cordero et al.,
2019). Thus, the median particle size increases during the warm seasons (summer/autumn) and decreases during the cold and mild seasons (winter/spring), it is about $258 \pm 27 \mu \mathrm{m}$ in some sandy beaches in Caribbean sea, but, $543 \pm 122 \mu \mathrm{m}$ in the Pacific side of Costa Rica (Sibaja-Cordero et al., 2019) . The difference is median particle size between seasons and has also been recognized by Bayed (2003). The increase of the organic matter observed after June 2017 is in strong relation with anthropogenic activities and those of construction that the ecosystem knows recently. In the sandy beaches of Costa Rica, the average value of organic matter found in sediment is $1.04 \pm 0.08 \%$ (Pacific side) and $2.25 \pm 0.55 \%$ (Caribbean side) (Sibaja-Cordero et al., 2019).

\section{Communities characterization of the macrozoobenthic biodiversity}

It was noticed from the DIMO model that the variation profile of the spring and summer (2016 and 2017) shows that the diversity H' is almost constant. In turn, the specific richness and the equitability J' vary; this type of community dynamics called "Diversity type". In winter and in autumn, the diversity H' and the specific richness are almost constant, but the equitability J' is almost variable, it is called the "Evenness type" dynamics of our community. Using the same model, these two types of communities are also found in the sandy communities of Bousselham lagoon (Bazairi et al., 2003). Donax trunculus clearly dominates the stations with $85.32 \%, 82.9 \%$ and $88.3 \%$ of the total abundance, respectively. 
Therefore, density is correlated with the trend of D. trunculus. In the same context, a study conduced in 39 beaches in north of Spain revealed 305 individuals as an average (Rodil et al., 2014). This dominance in the beach investigated in this study is related to the bimodal recruitment of this species, the ambient temperature for its biological development as well as the existence of the medium and fine sand suitable for its activities (mobility, filtering and breathing) (Bayed et al., 1988; Tlili et al., 2010; Lamine et al., 2020). Thus, the disparity between the species of every station is very frequent. This explains why the considered community exists in the stage "Pioneer 1" in the rank-frequency diagram. It can reveal that the winter period exhibits the lowest diversity and abundance compared to the other seasons. The highest values of biomass in summers and autumns are correlated to the existence of Cymbium cucumis known by its large body and the absence of this species in winter highly decreases the biomass values. Some studies, investigated the vertical distribution of biomass in the sediment, so they found that biomass was higher in sediments deeper than $15 \mathrm{~cm}$ as a consequence of larger individual sizes living deeper like C. cucumis (Celentanoa et al., 2019). At the same time, the ascending hierarchical clusters gave three logical gatherings. It shows that there are strong seasonal variations in the benthic community influenced by the ecological conditions of the environment (Bayed, 2003; Bazairi et al., 2003; Cherkaoui, 2005 ; Defeo et al., 2013 ; Limongi et al., 2020).

The faunistic structure of the benthic community revealed the $\mathrm{M}>\mathrm{C}>\mathrm{P}$ shape. Other studies (Gillet et al., 2003 and Bergayou et al., 2019 in the estuary of Oued Souss; Lefrere et al., 2015 in the lagoon of Oualidia) found almost the same structure. Conversely, in Bazairi et al. (2003) in the lagoon of Moulay Bousselham and Bayed et al. (1988) in the lagoon of Khnifiss revealed the $\mathrm{C}>\mathrm{P}>\mathrm{M}$ structure. In fifteen sandy beaches of the Moroccan Atlantic Ocean from Tangier to Terfaya, Bayed (1991) found that all the benthic communities are occupied mainly by crustaceans $(\mathrm{C}>\mathrm{P}-\mathrm{M})$. A total of 13,313 specimens were collected across the 39 beaches in north of Spain. The macrofaunal communities were dominated by crustaceans in terms of number of species ( 29 species, $41 \%$ ) and abundance (9854 individuals, 74\%), whereas molluscs showed the lowest contribution both, in terms of number of species and abundance (Rodil et al., 2014). In the Caribbean sea, sandy beaches revealed 6 species and in the Pacific side of Costa Rica beaches with a $\mathrm{C}>\mathrm{M}>\mathrm{P}$ shape (Sibaja-Cordero et al., 2019) and 9 species in an Uruguaian beach with the same shape (Limongi et al., 2020).

The trophic structure of the benthos is mainly characterized by the filtration of suspended elements, as the sediment is mostly populated by Donax trunculus. The omnivorous regime is assured by Portumnus latipes and Marphysa sanguina, in parallel, Cymbium cucumis and Natica royi are the only carnivorous predators that can exist in this environment. Macomangulus tenuis is the one who feeds on surfaces and the dead organic matter is consumed by Eurydice pulchra. It was noticed that there is diversity in regimes in this ecosystem. Almost the same trophic profile was found by Bayed et al. (1988) ; Bayed (1991) ; Bazairi et al. (2003) and Bayed (2003). In 39 beaches in Spain, D. trunculus occupied $97 \%$ of suspension feeding fauna. Suspension feeders, such as the burrowing bivalves of the Donax genus, are generally found in high abundance in exposed areas. They also found a considerable number of predators and scavengers that are crustacean species, for example the talitrid amphipods (Rodil et al., 2014). The trophic structure can be used to assess the functioning of communities in the post-installation state, because, the energy transfer and the cycling indicator is more efficient in the non-urbanized sectors than urbanized ones, as it was found by Costa et al.(2017).

\section{CONCLUSIONS}

The authors were able, through an integrated approach, to estimate a diagnosis of the biological and physico-chemical components of a sandy beach registered in a tourist development: the coastal ecosystem of Taghazout. The results reveal ten species and spatiotemporal variations with the absolute dominance of the Donax trunculus molluscan species. The physicochemical parameters show high seasonal variations and (PCA) analysis identified a perfect correlation between them. The sediment contains three grading classes (medium sand, fine sand, and very fine sand), the Trask index $\left(\mathrm{S}_{0}\right)$ shows that the sediment is very well classified with normal proportions of organic matter. It is observed that this last parameter is in an increasing state recently. Using the DIMO model, it can be recognized that the variation profile of the spring and summer (2016 and 2017) shows community 
dynamics called "Diversity type". In winter and in autumn, they are known as the "Evenness type". The rank-frequency diagram explains that the considered community exists in the stage "Pioneer 1 ". The clustering by (AHC) gave three logical gatherings of seasons. The faunistic composition of our benthic community revealed the dominance of molluscs. It can also be see that there is diversity in regimes in this ecosystem.

The results obtained in this study will constitute a database about the initial state of the sandy beach of Taghazout. Therefore, any future study aiming to assess the environmental impact of the tourist resort Taghazout bay on this coast after the implementation of this station and more exactly on the benthic macrofauna of the intertidal zone, will be complementary to our work. Similarly, the ecological data have been added to the directory of the early studies on the Moroccan Atlantic Coasts.

\section{Acknowledgments}

We thank the National Center for Scientific and Technical Research (CNRST) for funding this thesis project. I also thank the specialists who helped us in the species identification.

\section{REFERENCES}

1. Ana Maria, S., Vanin, P., Muniz, P., Cabrera De Léo, F. 2011. Benthic macrofauna structure in the northeast area of todos os santos bay, bahia state, brazil: patterns of spatial and seasonal distribution. Brazilian Journal of Oceanography, 59(1). 27-42. DOI: 10.1590/S1679-87592011000100003

2. Bachelet, G., Dauvin, J.C. 1993. Distribution quantitative de la macrofaune benthique des sables intertidaux du bassin d'Arachon. Oceanologica Acta (0399-1784), 16(1). 83-97. https://archimer.ifremer. fr/doc/00100/21133/

3. Bayed, A. 1991. Etude écologique des écosystèmes de plages de sable fin de la côte atlantique marocaine. Thèse d'État Es-Sciences, Université Mohammed V, Rabat. 215p.

4. Bayed, A. 2003. Influence of morphodynamic and hydrodynamic factors on the macrofauna of Moroccan sandy beaches. Estuarine, Coastal and Shelf Science, 58, 71-82. https://doi.org/10.1016/S02727714 (03)00050-7.

5. Bayed, A., Bazairi, A. 2008. Variations interannuelles de la macrofaune benthique des substrats meubles de la baie d'Oued Laou (Mer d'Alboran, Maroc). Travaux de l'Institut Scientifique, Rabat, série générale, n5, 99-106.
6. Bayed, A., El Agbani, M.A., Fekhaoui, M., Schouten, J.R. 1988. Benthos of soft substrates in the intertidal zone of the Khnifiss Lagoon: the Khnifiss lagoon and its surrounding environment (Province of La'youne, Morocco). Travaux d'institut scientifique, Rabat, hors-série. 71-80.

7. Bazairi, H., Bayed, A., Glémarec, M., Hily, C. 2003. Spatial organisation of Macrozoobenthic communities in response to environmental factors in a coastal lagoon of the NW African coast (Merja Zerga, Morocco). Oceanologica Acta, 26, 457-471. https:// doi.org/10.1016/S0399-1784(03)00041-0

8. Belal, A.A.M. 2019. Macro-benthic invertebrates as a bio-indicator for water and sediment quality in Suez Bay, Red Sea. Egyptian Journal of Aquatic Research, 45(2), 123-130. https://doi.org/10.1016/j. ejar.2019.03.003

9. Bergayou, H., 2006. Contribution à L'étude de L'écosystème de L'Estuaire de L'Oued Souss : Aspects Biologiques et écotoxicologiques. Mémoire D’Habilitation. Université Ibn Zohr, Agadir, p. 160.

10. Bergayou, H., Anajjar, E., Lefrere, L., Moukrim, A., Gillet, P. 2019. Recovery of an Estuarine Ecosystem after the Stopping of Wastewater Discharge: Intertidal Macrobenthic Community Characterization in the Estuary of Oued Souss (Southwestern Morocco). Ecological Engineering journal, 20(11), 133-145. https://doi.org/10.12911/22998993/112744

11. CEAEQ, 2003. Détermination de la matière organique par incinération : méthode de perte de feu (PAF), MA. 1010 - PAF 1.0. Ministère Environ. Québec 2003, 9.

12. Celentanoa, E., Lercaria, D., Maneiroa, P., Rodrigueza, P., Gianellia, I., Ortegab, L., Orlandoa, L., Defeo, O. 2019. The forgotten dimension in sandy beach ecology: Vertical distribution of the macrofauna and its environment. Estuarine, Coastal and Shelf Science 217, 165-172. https://doi. org/10.1016/j.ecss.2018.11.008

13. Chaouti, A., Bayed, A. 2005. Diversité taxonomique et structure de la macrofaune benthique des substrats meubles de la lagune de Smir. Travaux de l'Institut Scientifique, Rabat, série générale, $\mathrm{n}^{\circ} 4$, 33-42.

14. Cherkaoui, E., Bayed, A. 2005. Structure et distribution des peuplements benthiques intertidaux dans un estuaire d'Afrique du Nord : l'estuaire du Bou Regreg. Marine Life journal, 15(1-2), 29-41.

15. Costa, L.L., Tavares, D.C., Suciu, M.C., Rangel, D.F., Zalmon, I.R. 2017. Human-induced changes in the trophic functioning of sandy beaches. Ecological Indicators 82, 304-315. https://doi.org/10.1016/j. ecolind.2017.07.016

16. Defeo, O., Mclachlan,A. 2013. Global patterns in sandy beach macrofauna: Species richness, abundance, biomass and body size. Geomorphology, 199, 106114. DOI : 10.1016/J.GEOMORPH.2013.04.013 
17. Frontier S. 1976. Utilisation des diagrammes rangsfréquence dans l'analyse des écosystèmes. Journal de Recherche Océanographique, 1, 35-48.

18. Gillet, P., Gorman, E., Tallec, P., Moukrim, A., Mouloud, M., Ait Alla, A., Bergayou, H. 2003. Impacts des rejets urbains sur les communautés benthiques de l'embouchure de l'oued souss, baie d'Agadir, Maroc. Journal de Recherche Océanographique, 20, 39-44.

19. Gonzalez, S.A., Yanez-Navea, K., Munoz, M. 2014. Effect of coastal urbanization on sandy beach coleoptera Phaleria maculata (Kulzer, 1959) in northern Chile. Marine Pollution Bulletin, 83(1), 265-274. https://doi.org/10.1016/j.marpolbul.2014.03.042

20. Goransson, P. 2017. Changes of benthic fauna in the Kattega - An indication of climate change at midlatitudes. Estuarine, Coastal and Shelf Science, 194, 276-285. https://doi.org/10.1016/j.ecss.2017.06.034

21. Hily, C. 1987. Spatio-temporal variability of Chaetozone setosa (Malmgren) populations on an organic gradient in the Bay of Brest, France. Journal of Experimental Marine Biology and Ecology, 112(3), 201-216.

22. Horn, S., De la Vega, C. 2016. Relationships between fresh weight, dry weight, ash free dry weight, carbon and nitrogen content for selected vertebrates. Journal of Experimental Marine Biology and Ecology, 481, 41-48. https://doi.org/10.1016/j.jembe.2016.04.010

23. Hossain, M.B. 2019. Trophic functioning of macrobenthic fauna in a tropical acidified Bornean estuary (South East Asia). International Journal of Sediment Research, 34, 48-57. https://doi. org/10.1016/j.ijsrc.2018.08.002

24. Lamine, I., Ait Alla, A., Ben Haddad, M., Nadir, M., El Habouz, M., Moukrim, A. 2020. Population dynamics of Donax trunculus on the sandy beach of Taghazout (southern Morocco). Journal of Regional Studies in Marine Science, 33, 100912. https://doi. org/10.1016/j.rsma.2019.100912

25. Lamine, I., Ait Alla, A., Bourouache, M., Moukrim, A. 2019. Monitoring of Physico-Chemical and Microbiological Quality of Taghazout Seawater (Southwest of Morocco): Impact of the New Tourist Resort "Taghazout Bay". Journal of Ecological Engineering, 20(7), 79-89. https://doi. org/10.12911/22998993/109873

26. Lassalle, G., Lobry, J., Le Loc'h, F., Bustamante, P., Certain, G., Delmas, D., Dupuy, C., Hily, C., Labry, C., Le Pape, O., Marquis, E., Petitgas, P., Pusineri, C., Ridoux, V., Spitz, J., Niquil, N. 2011. Lower trophic levels and detrital biomass control the Bay of Biscay continental shelf food web: Implications for ecosystem management. Progress in Oceanography, 91, 561-575. http://dx.doi.org/10.1016/j. pocean.2011.09.002

27. Le Bris, H., Glémarec, M. 1996. Marine and brackish ecosystems of south Brittany (Lorient and Vilaine Bays) with particular reference to the effect of the turbidity maxima. Estuarine and Coastal Shelf Science, 42, 737-753.

28. Lefrere, L., Ouassas, M., Guillois, B., Gillet, P. and Moukrim A. 2015. Macrobenthic community structure of soft-bottom sediments in the Khnifiss lagoon, South of Morocco. Journal of Materials and Environmental Science, 6(11), 2226-2236.

29. Limongi, P., Carranza, A. 2020. Benthic macrofauna as an indicator of Ecological Integrity at an ocean beach with touristic purpose; Playa El Rivero, Punta Del Diablo, Rocha, Uruguay. Regional Studies in Marine Science, 39, 101441. https://doi. org/10.1016/j.rsma.2020.101441

30. Mokhtari, N., Mrabet, R., Lebailly, P., Bock, L. 2013. Spatialisation des bioclimats, de l'aridité et des étages de végétation du Maroc. Revue Marocaine des Sciences Agronomiques et Vétérinaires 2(1), 50-66.

31. Orlando, L., Ortega, L., Defeo, O. 2020. Urbanization effects on sandy beach macrofauna along an estuarine gradient. Ecological Indicators 111, 106036. https://doi.org/10.1016/j.ecolind.2019.106036

32. Pielou, E.C. 1966. Shannon's formula as a measure of specific diversity: its use and measure. American Naturalist, 100, 463-465.

33. Qinghong, L. 1995. A model for species diversity monitoring at community level and its application. Environmental Monitoring and Assessment, 34, 271-284.

34. Rodil, I.F., Compton, T.J., Lastra, M. 2014. Geographic variation in sandy beach macrofauna community and functional traits. Estuarine, Coastal and Shelf, 150(A), 102-110. https://doi.org/10.1016/j. ecss.2013.06.019

35. Shepard, F. 1954. Nomenclature based on sandsilcly ratios. Journal of Sedimentary Petrology, 24, 151-158.

36. Sibaja-Cordero, J.A., Camacho-Garcíaa, Y.E., Azofeifa-Solanoa J.C., Alvado-Arranzc, B. 2019. Ecological patterns of macrofauna in sandy beaches of Costa Rica : A Pacific-Caribbean comparison. Estuarine, Coastal and Shelf Science 223, 94-104, https://doi.org/10.1016/j.ecss.2019.04.032

37. Srinivas, T., Sukumaran, S., Mulik, J., Dias, H.Q. 2019. Community structure of benthic amphipods in four estuaries of northwest India. Regional Studies in Marine Science, 27, 100532. https://doi. org/10.1016/J.RSMA.2019.100532

38. Tlili, S., Metais, I., Boussetta, H., Mouneyrac, C. 2010. Linking changes at sub-individual and population levels in Donax trunculus: assessment of marine stress. Chemosphere, 81(6), 692-700. https:// doi.org/10.1016/j.chemosphere.2010.07.064

39. Trask, P. 1932. Origin and environment of source sediments of petroleum. Gulf Publishing Co., Houston, Texas, 19(1). 